\title{
A Grey Based Decision Making Approach for Supplier Selection
}

\author{
Sunita Gurung ${ }^{1}$, Ruben Phipon ${ }^{2}$ \\ ${ }^{1,2}$ (Department of Mechanical Engineering, SMIT, Majitar, Sikkim, India)
}

\begin{abstract}
Selecting a proper supplier is a crucial problem for the entire manufacturing company because of its strategic importance. Supplier selection problem is a multi-criteria decision making (MCDM) problem which involves both quantitative and qualitative factors, some of which conflict with each other. In order to satisfy the customers' demand, a good supplier must supply high-quality materials, deliver proper quantities of materials at right time, reduced costs and provide excellent services to the customers' requirement. Grey theory is a mathematical method based on the theory of Deng (1989) which was put forward in 1982. It is an effective method used to solve problems which involve discrete data and incomplete information. Due to the various advantages of Grey multiple attributes decision, this paper proposes an evaluation method to rank different suppliers based on multiple criteria. The overall performances of six suppliers are evaluated in this paper based on multiple criteria by using a Grey Relational Analysis method. The entire methodology is illustrated with the help of a case study and finally the rank of each supplier is determined according to its results and the optimal supplier is selected.
\end{abstract}

Keywords: Grey Relational Analysis, Supplier Selection.

\section{Introduction}

Supplier selection process is a multi-criteria decision making problem which is affected by several conflicting factors. This is a challenging task for professionals in the purchasing department and also for entire manufacturing companies since supplier selection is closely related to the purchasing department apart from other parts of the company. Suppliers supply direct and indirect raw materials to the manufacturing company thus they play a vital role in the supply chain. The company should make an effort to improve the total supply chain performance with the partners in order to stay in competitive environment and make profit in the market. Supplier selection is a strategic decision and it involves risk and the uncertainty because of its strategic importance and it requires the participation of decision-makers from marketing, finance and also from the other production departments in the selection process. One of the main goals of a manufacturing organization is having zero defects in production so it is important to minimize supply chain based problem in order to achieve this goal. Thus, supplier selection problem becomes complicated due to the uncertainties. Based on literature survey, four criteria namely quality, cost, delivery and warranty are selected which primarily effect the supplier selection process. Grey Relational Analysis (GRA) is widely used to solve the uncertainty problems under discrete data and incomplete information. In addition, GRA is one of the popular methods to analyze various relationships among the discrete data sets and make decisions in multiple attribute situations and also one of the best methods to make decisions under business environment. The main advantages of using GRA methods are:-

(i) It is suitable to handle both incomplete information and unclear problems.

(ii) It is used as an analysis tool when there is no enough data.

(iii) The calculations are simple and straightforward.

\section{Literature Review}

Ahmet Sarucan et al. (2011) proposed a solution procedure based on AHP and GRA to assess the renewable electricity generation technology alternatives. The individual levels of importance of the criteria are stated through the weights. Further this approach can be carried out to the similar multi-criteria decision making problems from other fields. Chih-Hung Tsai et al. (2003) presented a Grey Relational Analysis in Grey theory to establish a complete and accurate evaluation model for selecting vendors. The proposed model can be significantly used for further advanced in the method of evaluating vendors and also to improve purchasing cost and increase the production efficiency and overall competitiveness. Tugba Sari et al. (2016) explained the evaluation of fifteen certified suppliers of a food manufacturing company based on the specialized criteria (quality, price, delivery and warranty) by GRA method and the best supplier is selected according to their performance areas. Aravind Reddy et al. (2013) presented an AHP and Grey Relational Analysis to establish a complete and accurate evaluation model for selecting suppliers based on multiple criteria. Pooya Farahany (2013) used two distinct approaches Balanced Scorecard and Grey Relational Analysis which are used to create a precise, comprehensive model needed for selection of strategic suppliers. Davood Golmohammadi and Mahour Mellat Parast (2012) proposed a decision making model based on Grey Relational Analysis for supplier 
selection. The proposed model is able to provide more accuracy in comparison with other model and assist decision making to rank the alternatives. F. Cengiz Dikmen (2015) explained a Grey theory approach in selection of best supplier under uncertainty which deals with inaccurate, incomplete and imperfect information of expert judgment. Omid Jadidi et al. (2008) proposed a new grey based approach based on the concept of TOPSIS to deal with the supplier selection problem in an uncertain environment and selected the most desirable supplier considering both the ideal and negative ideal solution to solve the multiple attributes decision making problem. Ahmet Alp Senocak and Hacer Guner Goren (2016) presented a Fuzzy Grey Relational Analysis to determine the selection of appropriate suppliers and allocation of orders to them. They aslo presented a Fuzzy linear programming to determine the quantities of products to be provided by the suppliers. A.P.Khot and P.C.Kulkarni (2014) introduced a multi criteria decision making approach to determine the overall performance for each candidate supplier based on the characteristic demand of raw materials in order to select the most suitable vendors. Morteza Salehi Sarbijan and Mohsen Sayyah Markabi (2015) propose a model base on Grey theory under uncertainty. The proposed model can be applied to evaluate and select efficient suppliers under uncertainty conditions in which, decision makers' judgment on priority of inputs and outputs are independently integrated in to grey data envelopment analysis.

\section{Grey Relational Analysis}

Grey relational analysis (GRA) is a part of Grey system theory and the method was originally developed by Deng (1989). It is widely used to solve the uncertainty problems under the discrete data and incomplete information. GRA method is one of the very popular methods to analyze various relationships among the discrete data sets and make decisions in multiple attribute situations and, finally, it is one of the best methods to make decisions under business environment.

GRA consists of three steps. These steps are as follows:-

1. Generation of referential series.

2. Normalization of data sets.

3. Calculation of Grey Relational coefficient.

Formulae are as under:-

Larger the better value

$Z_{i j}=\frac{y_{i j}-\min \left(y_{i j}\right)}{\max \left(y_{i j}\right)-\min \left(y_{i j}\right)}$

Smaller the better value

$Z_{i j}=\frac{\max \left(y_{i j}\right)-y_{i j}}{\max \left(y_{i j}\right)-\min \left(y_{i j}\right)}$

Where, $\mathrm{ij}=1,2, \ldots . \mathrm{n}$

\section{Case Study}

A supplier selection decision is more complicated by the fact that various criteria must be considered in the decision making process. In this section, the performances of six suppliers are evaluated. The defined criteria are Quality, Cost, Delivery and Warranty. The proposed methodology is based on GRA approach for assessment and selection of suppliers. This method is suitable for solving the group decision-making problem in an uncertain environment.

Table 1: Alternatives vs. Criteria

\begin{tabular}{|c|c|c|c|c|c|}
\hline Sl. no & Suppliers & Quality & Cost & Delivery & Warranty \\
\hline 1 & A & $76 \%$ & 2350 & 5 & 1 \\
\hline 2 & B & $86 \%$ & 2100 & 4 & 2 \\
\hline 3 & C & $94 \%$ & 2500 & 3 & 1 \\
\hline 4 & D & $78 \%$ & 3099 & 5 & 1 \\
\hline 5 & E & $93 \%$ & 1999 & 4 & 3 \\
\hline 6 & F & $89 \%$ & 2405 & 3 & 2 \\
\hline
\end{tabular}

After forming a normal matrix, the stepwise procedure starts by construction of referential sequence. The reference sequence is defined as $\mathrm{X}_{0}=\left(\mathrm{x}_{1}(1), \mathrm{x}_{2}(2), \ldots, \mathrm{X}_{\mathrm{n}}(\mathrm{n})\right)$ and the aim of referential sequence is to find the closest sequence to the reference among the alternatives. The alternative vs. matrix for six suppliers can be represented as $\mathrm{X}_{\mathrm{i}}$ 


$$
X_{i}=\left\{\begin{array}{l}
0.76235051 \\
0.86210042 \\
0.94250031 \\
0.78309951 \\
0.93199943 \\
0.89240532
\end{array}\right\}
$$

$X_{0}$ as a referential series having optimal value for each criterion is given by $X_{0}=\{0.94,1999,3,3\}$

$\mathrm{X}_{0}$ is compared with the value of all alternative of each supplier.

\section{Normalization of Data}

The set of series data can be normalized using two approaches as shown below:-

(i) Larger value is better can be normalized using above formula (1)

(ii) Smaller the better value can be normalized using formula (2).

A group of assumptions are made for the following:

(i) Product Quality: Larger the better value.

(ii) Price: Smaller the better value.

(iii) Delivery Time: Smaller the better value.

(iv) Warranty: Larger the better value.

Table 2 Normalized data

\begin{tabular}{|c|c|c|c|c|c|}
\hline S1. no & Suppliers & Quality & Cost & Delivery & Warranty \\
\hline 1 & A & 0.0000 & 0.6809 & 0.0000 & 0.0000 \\
\hline 2 & B & 0.5556 & 0.9081 & 0.5000 & 0.5000 \\
\hline 3 & C & 1.0000 & 0.5445 & 1.0000 & 0.0000 \\
\hline 4 & D & 0.1111 & 0.0000 & 0.0000 & 0.0000 \\
\hline 5 & E & 0.9444 & 1.0000 & 0.5000 & 1.0000 \\
\hline 6 & F & 0.7222 & 0.6309 & 1.0000 & 0.5000 \\
\hline
\end{tabular}

Absolute difference $\Delta_{\mathrm{i}}(\mathrm{j})$ is the difference between a normalized entity and its reference is shown in table 3 .

Table 3: Absolute Difference.

\begin{tabular}{|c|c|c|c|c|c|c|}
\hline Sl. no & Suppliers & $\begin{array}{c}\text { Absolute } \\
\text { Difference } \Delta_{\mathrm{i}}(\mathrm{j})\end{array}$ & Quality & Cost & Delivery & Warranty \\
\hline 1 & $\mathrm{~A}$ & $\Delta_{1}$ & 0.9400 & 1998.3191 & 3.0000 & 3.0000 \\
\hline 2 & $\mathrm{~B}$ & $\Delta_{2}$ & 0.3844 & 1998.0919 & 2.5000 & 2.5000 \\
\hline 3 & $\mathrm{C}$ & $\Delta_{3}$ & 0.0600 & 1998.4555 & 2.0000 & 3.0000 \\
\hline 4 & $\mathrm{D}$ & $\Delta_{4}$ & 0.8289 & 1999.0000 & 3.0000 & 3.0000 \\
\hline 5 & $\mathrm{E}$ & $\Delta_{5}$ & 0.0044 & 1998.0000 & 2.5000 & 2.0000 \\
\hline 6 & $\mathrm{~F}$ & $\Delta_{6}$ & 0.2178 & 1998.3691 & 2.0000 & 2.5000 \\
\hline & & $\operatorname{Min} \Delta$ & 0.0044 & 1998.0000 & 2.0000 & 2.0000 \\
\hline & & $\operatorname{Max} \Delta$ & 0.9400 & 1999.0000 & 3.0000 & 3.0000 \\
\hline
\end{tabular}

The Grey Relational Coefficient can be calculated using the following formula:

$\mathrm{Y}_{\mathrm{i}}(\mathrm{j})=\frac{\Delta \min +\xi \Delta \max }{\Delta_{\mathrm{i}}(\mathrm{j})+\xi \Delta \max }$

Where, $\Delta_{\min }=\min _{\mathrm{i}} \min _{\mathrm{j}} \Delta_{\mathrm{i}}(\mathrm{j}), \Delta_{\max }=\max _{\mathrm{i}} \max _{\mathrm{j}} \Delta_{\mathrm{i}}(\mathrm{j})$ and $\boldsymbol{\xi}=$ distinguished coefficient $\boldsymbol{\xi} \in[0,1]$

Table 4: Grey Relational Coefficient values.

\begin{tabular}{|c|c|c|c|c|c|c|}
\hline Sl. no & Suppliers & $\begin{array}{c}\text { Grey Relational } \\
\text { Coefficient }\end{array}$ & Quality & Cost & Delivery & Warranty \\
\hline 1 & $\mathrm{~A}$ & $\mathrm{Y}_{1}$ & 0.3364 & 1.0000 & 0.7778 & 0.7778 \\
\hline 2 & $\mathrm{~B}$ & $\mathrm{Y}_{2}$ & 0.5552 & 1.0000 & 0.875 & 0.875 \\
\hline 3 & $\mathrm{C}$ & $\mathrm{Y}_{3}$ & 0.8950 & 1.0000 & 1.0000 & 0.7778 \\
\hline 4 & $\mathrm{D}$ & $\mathrm{Y}_{4}$ & 0.3652 & 1.0000 & 0.7778 & 0.7778 \\
\hline 5 & $\mathrm{E}$ & $\mathrm{Y}_{5}$ & 1.0000 & 1.0000 & 0.875 & 1.0000 \\
\hline 6 & $\mathrm{~F}$ & $\mathrm{y}_{6}$ & 0.6897 & 1.0000 & 1.0000 & 0.875 \\
\hline
\end{tabular}

After obtaining the grey relational coefficient, the grey relational grade is computed by averaging the grey relational coefficient corresponding to each performance criterion. The grey relational grade is calculated using the following formula:-

$Y_{i}=\frac{1}{n} \sum_{k=1}^{n} Y_{\mathrm{i}}(\mathrm{j})$. 
Where, $\gamma_{i}$ the grey relational grade for the ith experiment and $\mathrm{n}$ is the number of criteria.

Table 5: Shows the calculated grey relational grade in order to rank the suppliers

\begin{tabular}{|c|c|c|c|c|c|c|c|}
\hline S1. no & Suppliers & Quality & Cost & Delivery & Warranty & Grey relational grade & Rank \\
\hline 1 & A & 0.3364 & 1.0000 & 0.7778 & 0.7778 & 0.7230 & 6 \\
\hline 2 & B & 0.5552 & 1.0000 & 0.875 & 0.875 & 0.8263 & 4 \\
\hline 3 & C & 0.8950 & 1.0000 & 1.0000 & 0.7778 & 0.9182 & 2 \\
\hline 4 & D & 0.3652 & 1.0000 & 0.7778 & 0.7778 & 0.7302 & 5 \\
\hline 5 & E & 1.0000 & 1.0000 & 0.875 & 1.0000 & 0.9687 & 1 \\
\hline 6 & F & 0.6897 & 1.0000 & 1.0000 & 0.875 & 0.8911 & 3 \\
\hline
\end{tabular}

\section{Conclusion}

Supplier selection is an important issue in organizations since it is a decision making process based on multiple criteria. Besides it includes both qualitative and quantitative which conflict with each other. This paper presents a grey based decision making approach for supplier selection problem in an uncertain environment. In this case GRA method is used to solve the uncertainty problems under discrete data and incomplete information. This method is suitable for handling both unclear problems and incomplete information. The performances of six suppliers are evaluated in this paper against four criteria in order to select the suitable suppliers. Grey relational coefficient values and grey relational grade of the six suppliers are calculated and accordingly the suppliers are ranked. From the calculations, supplier E or C is selected as optimal supplier against the four criteria (Quality, Cost, Delivery and Warranty) because of their closer grey relational grade values. It is observed that the Grey based approach decision method is very precise on the whole. Therefore, the result of this study represents a further advance in the method of selecting proper suppliers. Further, more number of criteria may be taken into account while solving such problems for supplier selection.

\section{References}

[1] Deng, J., "Introduction to Grey System Theory", the Journal of Grey System (1989) Vol. 1, pp. 1-24

[2] Sarucan, Ahmet, Baysal, M. Emin, Kahraman, Cengiz, Engin, Orhan, A Hierarchy Grey Relational Analysis for Selecting the Renewable Electricity Generation Technologies, Proceedings of the World Congress on Engineering (2011) Vol. II, pp. 978-988

[3] Tsai, Chih-Hung, Chang, Ching-Liang, and Chen, Lieh, Applying Grey Relational Analysis to the Vendor Evaluation Model, International Journal of The Computer, The Internet and Management (2003), Vol. 11, No.3, pp. 45 - 53

[4] Sari, Tugb, Baynal, Kasım, Ergul, Oznur, Supplier Selection with Grey Relational Analysis, International Journal of Emerging Research in Management \&Technology (2016), Vol.5 Issue-4, pp. 61-70

[5] Reddy K, Veera Bahadur Aravind, T Reddy, Saras Chandra and Rajyalakshmi, G. Evaluation of Supplier Selection in Manufacturing Industries using Grey Relational Analysis- A Case Study, International Journal of Mechanical and Industrial Engineering(2013), Vol.3 Issue-2, pp. 61-66

[6] Farahany, Pooya, Evaluation and Selection of Strategic Suppliers using MBSC/GRA Combinational Model, Journal of Basic and Applied Scientific Research (2013),pp. 136-144

[7] Golmohammadi, Davood and mellat Parast, Mahour, Developing a grey-based decision making model for supplier selection, International Journal of Production Economics (2012), pp. 191-200

[8] Cengiz Dikmen, F, Grey theory approach in selection of the best supplier, Internal Journal of Business and Finance Management Research (2015), pp. 44-52

[9] Jadidi, Omid, Hong, Tang Sai, Firouzi, Fatemeh, Mohd Yusuff, Rosnah, An optimal grey based approach based on TOPSIS concepts for supplier selection problem, International Journal of Management Science and Engineering Management (2008) Vol. 4, pp. 104-117

[10] Senocak, Ahmet Alp and Guner Goren, Hacer, An Integrated Approach for Sustainable Supplier Selection in Fuzzy Environment, International Journal of Intelligent Systems and Applications in Engineering (2016), Vol.4, pp.130-135

[11] Khot, A.P and Kulkarni, P.C, Supplier Selection and Evaluation: A Multi Criteria Decision Making Approach, Spvryan's International Journal of Engineering Sciences \& Technology,(2014), Issue 2 Volume 1,pp. 1 - 5

[12] Markabi, Mohsen Sayyah and Sarbijan, Morteza Salehi, A Hybrid Model of Grey Relational Analysis and DEA Cross- Efficiency for the Evaluation of Decision Making Units, International Journal of Economy, Management and Social Sciences (2015), Vol.4, pp. 317-322

[13] Hou Juchi ,Grey Relational Analysis Method for Multiple Attribute Decision Making in Intuitionistic Fuzzy Setting, Journal of Convergence Information Technology (2010), vol.5, pp. 194-199

[14] Sarbijan, Morteza Salehi, and Markabi, Mohsen Sayyah, Using Grey Data Envelopment Analysis for Evaluation and Selection of Efficient Suppliers Based on Uncertainty, Management and Administrative Sciences Review, Volume 4, Issue 2 (2015) pp. 325-335 